\title{
The Differentiation of Certain Genera of Bacteriaceae by the Morphology of the Microcyst Stage
}

\author{
By K. A. BISSET \\ Department of Bacteriology, University of Birmingham
}

SUMMARY: The microcysts or resting cells of Bacteriaceae have three typical forms, which are regular and recognizable, and by which the Family may be divided into three groups.

The first type of microcyst is small, oval and eccentrically nucleate; it is typical of Bacterium coli, and Proteus, Pseudomonas and Salmonella spp. with the exception of Salm. typhi which forms a very large, oval microcyst, with a central nucleus. The microcysts of Shigella spp. resemble those of Salmonella typhi. Bacterium aerogenes produces large, spherical or oblong microcysts with a small, central nucleus.

It has for long been bacteriological dogma that the members of the large group of Gram-negative, non-sporing bacteria are morphologically almost indistinguishable, apart from the presence or absence of flagella or capsules, and in some cases, the arrangement of flagella. While this is approximately true of the vegetative cell, the morphology of the resting cell, which in this family closely resembles the microcyst of myxobacteria (Bisset, 1949, 1950), appears to provide a criterion of considerable systematic value. It has already been observed that a striking difference exists between the microcyst of Bacterium coli and Bact. aerogenes, the latter being much larger. The present paper is intended to extend these observations and to indicate the degree to which they may be correlated with other criteria used in classification.

\section{METHODS AND MATERIALS}

In almost every case the bacteria examined were newly isolated. I consider that such delicate, morphological comparisons should not be made upon material which has been cultivated artificially for longer than is absolutely necessary. Where this ideal was difficult to achieve, as in the case of Salmonella typhi, observations made originally upon newly isolated strains were confirmed, as far as possible, upon stock cultures of the same species.

Cultures were made upon nutrient agar. They were incubated at $37^{\circ}$ for $24 \mathrm{hr}$. and afterwards stored at $20^{\circ}$. Mature resting cells appeared in such cultures after a period varying from a few days to 6 weeks or more. Preparations were stained by the acid-Giemsa or methylene-blue eosin techniques (Bisset, 1950), and were mounted in water for examination.

\section{RESULTS}

Differentiation of Bacterium coli from Bacterium aerogenes

Fifty strains of lactose-fermenting bacteria were isolated from human and animal faeces, soil, and plant surfaces. Of these strains twenty-seven were indole-positive and Voges-Proskauer negative, motile and non-capsulated. 
Twenty-three were indole-negative and Voges-Proskauer positive, non-motile and capsulated. The former will hereafter be referred to as Bact. coli, the latter as Bact. aerogenes. One strain of Bact. coli differed from the remainder in the production of a voluminous slime layer. This, however, was not a capsule according to the criteria of Klieneberger-Nobel (1948), as it was irregular in outline. This organism, like the other coli strains, was motile, which I consider, in this Order, to be synonymous with flagellated.

The morphology of the microcyst stage was in complete accordance with

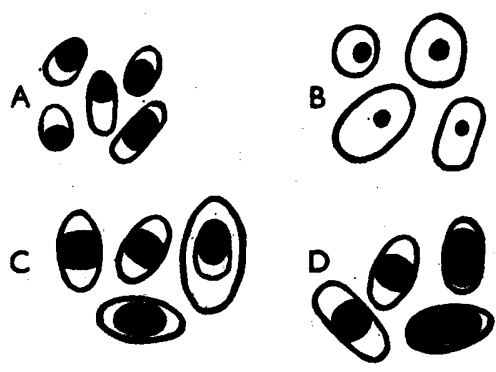

Fig. 1. Microcysts of Bacteriaceae. A, coli type (Bact. coli, Salmonella, Proteus, Pseudomonas). B, aerogenes type. C, S. typhi. D, Shigella.

this grouping. The microcysts of Bact. coli were relatively small, elongate ovals, and the nucleus stained eccentrically (Fig. 1 A; Pl. 1, figs. 1, 2). They were approximately half the size of young, vegetative bacteria of the same species. The microcysts of Bact. aerogenes were from 1.5 to 3 times as great as those of Bact. coli, spherical or oblong in shape, often retaining the capsule to some extent, and with small, central nuclei (Fig. 1B; Pl. 1, figs. 3, 4). This difference is so striking that these two species may readily be distinguished by the simple, microscopic examination of mature cultures. In order to check this important point, I examined these fifty strains, stained and numbered by another person, and identified them correctly by this means alone. It was even possible to detect preparations made from mixed cultures, and containing both coli and

aerogenes type microcysts. In three cases, hitherto unsuspected, contamination of cultures was revealed in this way, and their unusual biochemical behaviour explained. A possible source of error is excessive age of cultures. All types of microcyst may be distorted by desiccation and become difficult to identify.

About a dozen strains of lactose-fermenting bacteria, derived from the faeces of animals and from vegetation, failed to conform exactly to either of these groups. Some produced indole, although non-motile; in others the macroscopic appearance of the colony was markedly unlike that of typical coli or aerogenes, and the vegetative cell was small and irregular in form. Most of these possessed large microcysts with central nuclei, like aerogenes, but spherical, oval or irregular in shape.

\section{Salmonella}

Eighteen strains of Salmonella were examined, of which twelve were newly isolated. These included Salm. paratyphi B and C, and Salm. enteritidis. All possessed the type of microcyst characteristic of Bacterium coli, i.e. small, oval, and eccentrically nucleate. The morphology of the eight strains of Salmonella typhi-murium, which were examined, was unusual. The typical primary nucleus (Bisset, 1950) was not seen at any stage; the vegetative nucleus was 
large and irregular. This condition is more often found in Bacterium aerogenes than in Bact. coli, but the microcysts of Salmonella typhi-murium, where they occurred, appeared to be of the coli type.

\section{Salmonella typhi and Shigella}

The microcyst of Salm. typhi was different from that of other salmonellas, or indeed from:either of the previously mentioned types. Fourteen strains were examined; six had been in laboratory culture for only a few months, eight were stock cultures. In the newly isolated strains, and in the majority of the stock cultures (probably the most recently isolated), the microcysts were approximately the same size as those of Bacterium aerogenes, but were oval in shape and had large, central nuclei; some microcysts were relatively enormous (Fig. 1C; PI. 1, figs. 5-7). These exceptionally large cells possessed nuclei which were, correspondingly, so large that their vesicular structure was clearly visible (Pl. 1, figs. 6, 7). Three of the stock cultures failed to produce recognizable microcysts.

The appearance of the microcysts of Shigella which were examined (ten Sh. flexneri, six Sh. sonnei, one Sh. schmitzii and one Sh. alkalescens), all of which were newly isolated, was very similar to that of the smaller microcysts of Salmonella typhi, but the nucleus was often irregular in shape (Fig. 1D; Pl. 1, fig. 8). In cultures of Shigella sonnei occasional microcysts were irregular in outline, but were recognizable as representatives of the same morphological type.

\section{Proteus and Pseudomonas}

Five newly isolated strains of Proteus vulgaris, six of Pr. morganii, four of Pseudomonas fluorescens, and five (four newly isolated) of Ps. pyocyanea, all possessed the coli type of microcyst.

\section{DISCUSSION}

In most branches of biology, the characteristics of the reproductive process are of primary importance in classification; it is justifiable to claim that the morphology of the microcysts of various genera of Bacteriaceae may provide evidence of their relationship. This criterion is already employed in the classification of myxobacteria.

On this basis, Bacterium coli and Bact. aerogenes are unlike, and, as their differences, both in the morphology of the vegetative bacterium and in their biochemical reactions, are more marked than their resemblances, the recognition of the genus Aerobacter is probably justifiable. Bacterium coli is morphologically identical with Salmonella (except Salm. typhi), and shares the habit of gut parasitism. The coli type microcyst is found also in Proteus and Pseudomonas, but in these genera the vegetative form is distinct. Bacterium aerogenes forms a group with a number of similar bacteria from the soil.

Salmonella typhi and Shigella resemble each other in their habitat in man, and in their failure to produce gas in the fermentation of carbohydrates. The latter characteristic is shared by the $S$ h. pullorum group, which are antigenically 
related to Salmonella typhi, and like Shigella, are non-motile. Newly isolated cultures were unfortunately not available. The resemblance in microcyst form between Salmonella typhi and Shigella may be regarded as additional evidence of relationship.

\section{REFERENCES}

Bisset, K. A. (1949). The nuclear cycle in bacteria. J. Hyg., Camb., 47, 182.

Brsset, K. A. (1950). The cytology and life-history of bacteria. Edinburgh: Livingstone. KuIEneberger-Nobel, E. (1948). Capsules and mucoid envelopes of bacteria. J. Hyg., Camb., 46, 345.

\section{EXPLANATION OF PLATE}

(All stained by acid-Giemsa, except fig. 4, stained by methylene-blue eosin. Magnification $\times$ 3000.)

Figs. 1, 2. Microcysts of Bacterium coli. Proteus, Pseudomonas and Salmonella (except Salm. typhi) are similar.

Figs. 3, 4. Microcysts of Bacterium aerogenes.

Figs. 5-7. Microcysts of Salmonella typhi. These more closely resemble the microcysts of Shigella than of other species of Salmonella.

Fig. 8. Microcysts of Shigella schmitzii.

(Received 23rd December, 1949) 
Journal of General Microbiology, Vol. 4, No. 3

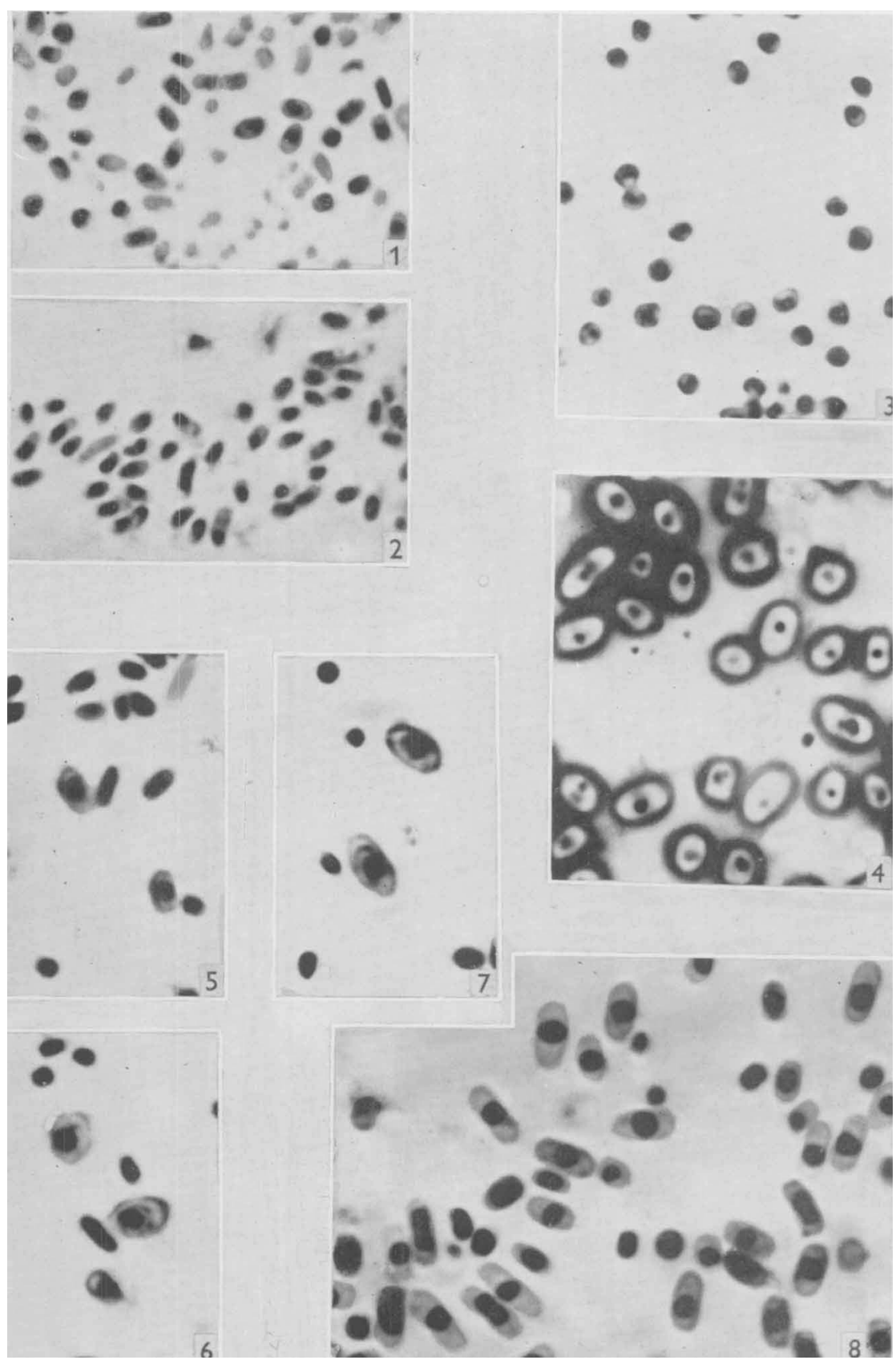

K. A. Bisset - The differentiation of certain genera of Bacteriaceae by tife morphology of the microcyst stage. Plate 1 